\title{
EXPERIÊNCIA E SIGNIFICADO DE MENTORIA: DA ABORDAGEM SOCRÁTICA À NOVA CIÊNCIA DA APRENDIZAGEM ${ }^{1}$
}

\author{
MENTORING EXPERIENCE AND MEANING: FROM THE SOCRATIC \\ APPROACH TO THE NEW SCIENCE OF LEARNING \\ EXPERIENCIA Y SIGNIFICADO DE LAS TUTORÍAS: DEL ENFOQUE \\ SOCRÁTICO A LA NUEVA CIENCIA DEL APRENDIZAJE
}

\section{Liv Mjelde*}

*Professora emérita em Pedagogia da

Educação Profissional no Centro Sênior da Universidade Metropolitana de Oslo. É socióloga por formação e especialista em Sociologia da Educação, estudando especialmente as mudanças nas relações entre ensino profissional e geral a partir das perspectivas psicológica (formas de conhecimento), didática (aprendizagem em oficinas e aulas) e sociológica (divisão do trabalho mental e manual). Um de seus campos de pesquisa são as divisões de gênero, pois pode-se observá-las diretamente no ensino profissional, nos campos profissionais masculino e feminino, em relação aos movimentos no mercado de trabalho e ideologia da família. Publicou em vários idiomas e foi a palestrante principal em muitas conferências internacionais. A avaliação dos programas Leonardo da Vinci para a Comissão da União Europeia fez parte de seu trabalho. Foi líder do projeto norueguês na Universidade de Kyambogo, Kampala, Uganda (2007-2011), desenvolvendo um mestrado em Pedagogia da Educação Profissional com estudantes de Uganda e Sudão do Sul. É conselheira da Associação Europeia de Professores Eméritos. Seu último livro (2018) é sobre a Segunda Guerra Mundial: Secrets in a Pair of Scissors. Wartime Russian Women's labour and Life in Prison Camps in Northern Norway 1942-1945 (Segredos em uma tesoura. O trabalho das mulheres russas em tempos de guerra e a vida nos campos de prisioneiros no norte da Noruega 1942-1945, em tradução livre). Website: www.livmjelde.net. Oslo, Noruega. E-mail:mjeldeliv@gmail.com

Recebido para publicação em 29.5.2020

Aprovado em 26.6.2020

\section{Resumo}

A mentoria como práxis desejada nas organizações de ensino chegou à frente das discussões sobre aprendizagem e ensino nas últimas décadas. A mentoria como conceito em teoria educacional na tradição europeia está ligada ao que foi chamado de Método Socrático. O mestre-professor é uma pessoa de experiência com quem os jovens podem conversar. Perguntas e reflexões devem desenvolver a curiosidade e o engajamento dos estudantes na busca de novos conhecimentos. Esse entendimento de conhecimento e aprendizagem corresponde a um modelo de aprendizagem em que a atividade prática é a base para aprender. Contradições entre perspectivas sobre formas de aprender são uma questão central em nossa época. Neste artigo, discutese essa problemática no contexto do trabalho científico de John Dewey, Célestin Freinet, Paulo Freire, Maria Montessori e Lev Vygotsky.

Palavras-chave: Divisão social do conhecimento. Práxis e conhecimento armazenado. Mentores e aprendizagem. Pedagogia da educação profissional. Pedagogia das profissões.

\section{Abstract}

Mentoring as a desired praxis in educational organizations has come to the forefront in discussions about learning and teaching in recent decades. Mentoring as a concept in educational theory in the 
European tradition is connected to what has been called the Socratic Method. The master-teacher is a person of experience with whom young people can converse. Questions and reflections should develop students' curiosity and engagement in the search for new knowledge. This understanding of knowledge and learning corresponds with an apprenticeship model of learning where "hands-on activity" is the basis for learning. Contradictions between outlooks on ways of learning are a central issue in our times. This article discusses this problematic here in the light of the scientific work of John Dewey, Célestin Freinet, Paulo Freire, Maria Montessori, and Lev Vygotsky.

Keywords: The Social Division of Knowledge. Praxis and Stored Knowledge. Mentors and apprenticeship. Vocational Pedagogy. Pedagogy of Professions.

\section{Resumen}

La tutoría como práctica deseada en las organizaciones educativas ha pasado a un primer plano en los debates sobre el aprendizaje y la enseñanza en las últimas décadas. La tutoría como concepto en la teoría educativa de la tradición europea está vinculada con el denominado «método socrático». El maestro-docente es una persona con experiencia con la que los jóvenes pueden conversar. Las preguntas y reflexiones deben suscitar la curiosidad y el compromiso de los estudiantes en la búsqueda de nuevos conocimientos. Este entendimiento del conocimiento y el aprendizaje se corresponde con un modelo de enseñanza en el que la «actividad práctica» es la base del aprendizaje. Las contradicciones entre las distintas perspectivas de las formas de aprendizaje son un tema central en nuestros tiempos. El presente trabajo habla de esta problemática a la luz del trabajo científico de John Dewey, Célestin Freinet, Paulo Freire, Maria Montessori y Lev Vygotsky.

Palabras clave: La división social del conocimiento. Práctica y conocimientos almacenados. Tutores y aprendices. Pedagogía de la formación profesional. Pedagogía de las profesiones.

\section{Introdução}

Nas últimas décadas, o desenvolvimento de tecnologias sofisticadas trouxe mudanças revolucionárias ao trabalho da mão e da mente. Isso ocorre em profissões práticas e constitui um desafio ao trabalho científico e à arte de ensinar. A expansão da educação em instituições formais após a Segunda Guerra Mundial criou novas questões fundamentais sobre a aprendizagem e o ensino. A revolução tecnológica baseada nas Tecnologias da Informação e da Computação (TICs) está reestruturando a produção a uma velocidade acelerada e mudando constantemente os processos de trabalho, criando, ao mesmo tempo, novas demandas de habilidades em todos os nichos de negócios e profissões. Negócios antigos desaparecem e novos se desenvolvem. Esses desenvolvimentos desafiam as práticas tradicionais 
de ensino e aprendizagem, assim como a tradicional divisão social do conhecimento; as divisões entre trabalho mental e manual; entre a chamada teoria e prática; entre a aprendizagem nas escolas e a aprendizagem no trabalho; assim como entre a sala de aula acadêmica e as tradições do mestrado na educação formal. Ambas se encontrarão? As complexas contradições entre a aprendizagem "mão na massa", que cresceu das guildas medievais, e as aulas tradicionais apresentadas nas salas de aula, advindas das escolas de catedrais na Idade Média, são a questão central deste artigo.

A estrutura

de classes da nossa sociedade é altamente visível
Na Noruega, há 60 anos, as universidades eram o domínio de uma pequena elite. A maioria das pessoas tinha sete anos de ensino obrigatório. ${ }^{2}$ Com o desenvolvimento do capitalismo industrial da Noruega, o ensino e a capacitação profissional da classe trabalhadora eram realizados em escolas técnicas/profissionalizantes, onde a aprendizagem prática em workshops era central, como já era, há muito tempo, no caso de aprendizagens no local de trabalho. A característica do sistema escolar na Escandinávia no período pós-guerra é a expansão quantitativa do ensino público e o objetivo declarado de eliminar as diferenças de classe na sociedade por meio do sistema educacional. Os antigos ginásios acadêmicos e as escolas técnicas/profissionalizantes foram integrados em uma lei comum do ensino médio na Noruega em 19743. "Igualdade por meio da educação" era o slogan, e a expansão tornou-se uma regra. Uma demanda por justiça social também fazia parte do argumento.

Hoje em dia, os jovens devem completar treze anos de escolaridade formal antes de entrar no mercado de trabalho e/ou instituições de ensino superior. $50 \%$ da coorte entra em várias áreas acadêmicas e $50 \%$ em áreas técnicas/profissionalizantes. Isso faz parte de uma tendência global que, entre outras coisas, baseia-se na crença de que a expansão da igualdade de acesso e direitos ao ensino superior resolveria as diferenças de classe. A realidade mostrou as complexidades dessas questões (BOURDIEU; PASSERON, 1964; GRIGNON, 1971; LIVINGSTONE, 1987; MJELDE, 1987, 1990, 2015).

A estrutura de classes da nossa sociedade é altamente visível e um dos principais fatores que a molda e reproduz é o processo de classificar e estabelecer distinções por meio do sistema educacional. A classe trabalhadora tem acesso ao ensino superior se seguir os caminhos acadêmicos. Esses caminhos dão acesso às universidades, enquanto os caminhos técnico-profissionalizantes dão acesso a trabalhos qualificados em um mercado de trabalho manual em constante mudança. Os jovens que escolhem a via profissionalizante/técnica para se tornarem trabalhadores qualificados não têm acesso ao ensino universitário. Parte de uma longa luta conduzida pelos sindicatos tem sido a demanda por reconhecimento formal da importância e validade da educação profissional/técnica. A requalificação dos trabalhadores ocorre por meio de cursos de formação de adultos, sem atribuir pontos que dariam acesso ao ensino superior. As comissões da realeza e as propostas no Parlamento sobre habilidades e competências têm abordado essa 
problemática repetidamente. A última proposta, chamada "Aprendendo ao longo da vida", foi aprovada pelo governo em 22 de abril de 2020 e declara que "A reforma de competências: aprendendo ao longo da vida tem o objetivo de que ninguém seja deixado para trás por falta de competência" (NORWAY, 2020).

Parte do problema nessa expansão da escolaridade é o fracasso significativo de muitos jovens em se adaptarem ao sistema escolar e encontrarem um ponto de apoio no mercado de trabalho. As dificuldades de aprendizagem e as taxas de evasão escolar têm sido substanciais tanto nas escolas secundárias quanto no ensino superior nas últimas décadas. Para professores e orientadores das próximas gerações, isso criou novos desafios e a necessidade de desenvolverem ideias e práticas revolucionárias para a vida cotidiana. A questão é como tornar a aprendizagem significativa para todos os jovens que pretendem ter uma vida plena em qualquer profissão ou negócio, em que estejam iniciando. Isso está no centro das discussões, não apenas na Europa, mas também em outras partes do mundo (MJELDE, 2015a, 2017).

\section{A Estratégia de Lisboa e a educação profissional}

No século atual, chamou-se a atenção na Europa para as vantagens do ensino para o crescimento econômico em uma economia globalizada. A Estratégia de Lisboa, também conhecida como Agenda de Lisboa ou Processo de Lisboa, foi um plano de ação e desenvolvimento elaborado em 2000 para ser aplicável à economia da União Europeia entre 2000 e 2010. Seu objetivo era tornar a União Europeia a economia baseada em conhecimento mais competitiva do mundo, capaz de crescimento econômico sustentável, com mais e melhores empregos e maior coesão social. Os principais conceitos usados nesses documentos foram "A Sociedade do Conhecimento" e "A Economia da Aprendizagem". A inovação deveria ser o motor da mudança social. Mas a crise econômica mostrou que os objetivos estão longe de serem alcançados. Parte da Estratégia de Lisboa era reduzir as taxas de evasão escolar. Pesquisas na Escandinávia, como em outras partes do mundo, mostram que a taxa de evasão escolar no ensino profissionalizante e superior continua a ser um desafio.

A inovação

deveria ser

o motor da

mudança social

Mas o ensino profissionalizante e a aprendizagem nas escolas estão em foco de um novo jeito. Os documentos de Lisboa enfatizam a chamada economia do conhecimento, a qual, por sua vez, concentrou a atenção no ensino profissionalizante e nas taxas de evasão escolar. 0 Ministro do Conhecimento norueguês apresentou um relatório parlamentar sobre educação, em março de 2013, enfatizando que será dada mais atenção às questões profissionais. O governo pretende reduzir os grandes problemas atuais de evasão. Esse Relatório Oficial da Noruega (NORWAY, 2013?) constatou que $30 \%$ dos estudantes não concluíram o ensino médio (coorte de 16 a 19 anos) no tempo certo e que a maior taxa de evasão escolar ocorre no setor profissionalizante. O relatório apontou que, se a taxa de conclusão dos estudantes aumentasse de 70 para $80 \%$, reduziria os custos com educação entre 5,4 e 8,8 bilhões 
de coroas norueguesas por coorte (NORWAY, 2013?, p. 174). O dinheiro da pesquisa foi canalizado para questões educacionais, tanto no ensino fundamental quanto no ensino médio. Houve um interesse maior no que se conhece hoje por pesquisa baseada em evidências na educação profissional e uma nova atenção está sendo dada ao fato de que treze anos de ensino, longe da vida profissional, criou um novo conjunto de problemas (BAKKEN; ELSTAD, 2012; MJELDE, 2017). ${ }^{4}$

As principais conclusões de minha pesquisa no setor de educação profissional nas últimas décadas mostram que os estudantes e aprendizes de cursos profissionalizantes prosperaram e aprenderam quando estavam em atividade nas oficinas da escola profissionalizante ou no local de trabalho, ao passo que encontraram pouco significado ou relevância para as muitas horas passadas nas salas de aula de ensino geral. Eles compareceram nas oficinas, mas não conseguiram frequentar as aulas acadêmicas (MJELDE, 1993, 2006).

\section{As tradições contraditórias nos sistemas educacionais atuais}

A educação do ensino médio, ainda hoje, continua moldada em duas tradições que resultam da forma como a instrução dos jovens foi organizada durante a Idade Média. De um lado, as tradições escolares originárias das escolas catedrais e, de outro, as tradições artesanais dos mestres/aprendizes que ensinavam os conhecimentos práticos desenvolvidos no sistema de guildas. Os professores acadêmicos recebiam formação em suas disciplinas nas universidades, enquanto os docentes do ensino técnico-profissionalizante tinham treinamento em programas de aprendizagem e pelo próprio mercado de trabalho. As contradições que se pode observar entre essas diferentes tradições de aprendizado fazem parte da divisão social do conhecimento na sociedade capitalista atual. Mas as rápidas mudanças no mercado de trabalho exigem novas soluções nos sistemas educacionais. Atualmente, o pré-requisito para a mudança em toda a ciência de aprendizagem e ensino é a necessidade de uma compreensão mais profunda dessas complexidades.

Na pedagogia, a contradição e a necessidade de mudanças criaram muitas escolas de pensamento e experiências pedagógicas nos últimos cem anos. A busca por "Uma pedagogia para as pessoas" criou novas práticas com o objetivo de transcender as contradições em um mundo profundamente bifurcado na década de 1920. Uma das conhecidas experiências europeias foi a escola Bauhaus, na Alemanha. Walter Gropius fundou essa escola de design alemã em Weimar, em 1919, inspirado nas tradições de aprendizagem. Não haveria "professores e alunos" na escola Bauhaus, e sim "mestres, artesãos e aprendizes" trabalhando e aprendendo juntos em oficinas. A prática e a cooperação estavam no centro da aprendizagem. Quando os nazistas chegaram ao poder em Weimar, em 1925, Gropius mudou a escola para a cidade industrial de Dessau, Alemanha. Em 1932, tropas de choque nazistas ocuparam a escola, destruíram muito do que encontraram e criaram um local de treinamento para oficiais. A escola mudou-se, por um breve período, para 
Berlim, mas, um ano depois, esse local também foi invadido e fechado definitivamente (CHIASSON, 2019).

Contudo as ideias circularam rapidamente para outros países. Josef Albers, um jovem professor, havia se matriculado como aluno na Bauhaus, em Weimar, em 1920. Em 1925, ele foi o primeiro aluno da Bauhaus a ser convidado a ingressar no corpo docente. Em 1933, quando a pressão dos nazistas obrigou a escola de Berlim a fechar suas portas, Josef Albers havia se tornado um dos artistas e professores mais conhecidos da Bauhaus. Josef e sua esposa, Anni, foram convidados, em novembro de 1933, para ir à recém-criada Black Mountain College, na Carolina do Norte, e compartilhar as experiências que tiveram a partir de Gropius. A escola Bauhaus havia sido um centro de treinamento para profissionais, onde o trabalho manual, na produção artesanal, estava no centro da aprendizagem. A Black Mountain College era uma escola de estudos gerais, preocupada em como transcender os hábitos tradicionais de aprendizagem, com base na divisão entre "Mão, Mente, Coração". Muito do que Albers trouxe da tradição da Bauhaus, na Alemanha, era compatível com o espírito da Black Mountain College: os princípios de "prática antes da teoria", "aprender fazendo", "o melhor ensino é a própria experiência" e "a experiência supera o estudo". Albers mudou seus objetivos do ensino de competências profissionais para o ensino de todo o ser humano, como ele expres-

Pensar por si

mesmo é o objetivo principal do ensino sou. Ele elogiou a afirmação de John Dewey de que a arte deve ser integrada ao currículo geral e que pensar por si mesmo é o objetivo principal do ensino. De acordo com Adamson (2007), não é o domínio da teoria que proporciona o aprendizado, e sim a experiência indutiva da prática.

Esse modo de pensar é originário das tradições dos mestres da aprendizagem artesanal na Idade Média e foi uma inspiração para os cientistas da educação no século passado. "Aprender fazendo" foi uma das maneiras pelas quais os reformadores pedagógicos tentaram resolver os problemas inerentes aos sistemas de escolas públicas da sociedade industrial do século XX. Nos EUA, John Dewey fundamentou um movimento de reforma nessa base, assim como Célestin Freinet com suas gráficas na França. Dewey e Freinet esboçaram seus modelos educacionais com base em atividades e trabalhos em oficinas. Seus modelos foram baseados em uma profunda compreensão dos seres humanos como agentes ativos que se desenvolvem por meio de atividades filogenéticas e ontogenéticas. Outra característica comum de John Dewey e Célestin Freinet foi o desejo de praticar o que eles pregavam. Ambos procuraram ter suas teorias testadas na prática. Dewey fundou a Escola-laboratório em Chicago. Enquanto isso, na França, Freinet começou suas escolas de artes gráficas. Os dois tinham em comum um modelo pedagógico baseado na crença de que o aprendizado ocorre durante a atividade real das pessoas em suas vidas cotidianas (MJELDE, 1997). "Aprender fazendo" é um conceito bem conhecido das escolas-laboratório de John Dewey. Ele afirma: "há uma forma de teoria inútil que se opõe à prática. A verdadeira teoria científica está localizada dentro dos limites 
da prática e funciona como o ímpeto para a expansão, proporciona orientação para novas possibilidades" (DEWEY; DEWEY, 1962). Ele apresenta um modelo de oficina de aprendizagem baseado na prática e na cooperação. Essas complexidades da teoria e da prática fazem parte das discussões e a mentoria é um dos conceitos mais recentes no debate educacional atual.

\section{Mentoria e o método Socrático}

A natureza e os métodos de aprendizagem estão em discussão desde a época dos antigos gregos, quando Aristóteles, Platão e Sócrates eram as fontes de inspiração mais notáveis. É caso para se perguntar: por que as experiências de estudantes e aprendizes profissionais relacionadas à aprendizagem e significado no contexto de oficinas e na vida profissional contrastaram de modo tão acentuado e negativo com as da escola onde a aprendizagem ocorre nas salas de aula? A prática nas tradições de mestre/aprendizagem e mentoria pode estar desempenhando um papel fundamental nesse sentido. 0 conceito de mentoria foi inspirado na mitologia grega. 0 personagem de Mentor na Odisseia, de Homero, deu vida ao conceito. Embora o verdadeiro Mentor da história seja um velho um tanto ineficaz, a deusa da Guerra e da Sabedoria, Athena, assume sua aparência para guiar o jovem Telêmaco em seu momento de dificuldade. Por meio de suas ações, ela é a sábia mentora do jovem e agiu como conselheira sábia e confiável, ajudando Telêmaco a crescer em experiência, maturidade e coragem. A palavra surgiu no idioma inglês em 1750, quando foi traduzida a história do arcebispo François Fénelon, Les Aventures de Telemache (As aventuras de Telêmaco), na qual o Mentor é o personagem principal. O livro de Fénelon se tornou o livro mais republicado do século XVIII, levando a palavra "mentor" a ser ressuscitada após o intervalo de quase três milênios (PAVLOPOULOS, 2020).

A transformação socrática

envolvia 0 respeito pela competência e o trabalho dos praticantes
A mentoria como um conceito em teoria educacional atual está intimamente ligada ao que é chamado de Método Socrático. O papel do professor era ser um interlocutor, um parceiro com quem os jovens podiam conversar, discutir e analisar. Perguntas e reflexões devem ajudar a desenvolver a curiosidade e o engajamento dos jovens na busca de novos conhecimentos com base em seu meio material, em suas ações, ideias relacionadas e hipóteses. Por meio de conversas e perguntas e respostas, os entendimentos e percepções inerentes dos participantes são elaborados, esclarecidos e aprofundados. Graças ao aluno de Sócrates, Platão, e ao famoso aluno de Platão, Aristóteles, o método socrático chegou até nós. Outra parte de seu pensamento, a transformação socrática, implicava afastar-se do mero conhecimento perceptivo e tentar explicações mais amplas e comparativas de coisas externas. A transformação socrática envolvia o respeito pela competência e o trabalho dos praticantes em várias esferas da vida. Aristóteles, seguindo Sócrates e Platão, desenvolveu seu pensamento sobre a aprendizagem, tomando a competência artesanal prática como seu ponto de 
partida e modelo "autoevidente". O conceito aristotélico de frônese, geralmente traduzido como "prudência", "sabedoria prática" ou "julgamento", está sendo redescoberto por muitos cientistas de diferentes disciplinas nas últimas décadas (EIKELAND, 2008). Linda Cooper (2018), da Universidade da Cidade do Cabo, descobriu que havia uma ignorância e falta de conscientização da variedade de conhecimentos na sociedade sul-africana. O ensino formal enfatiza o conhecimento conceitual, enquanto o ensino profissional e a aprendizagem no local de trabalho enfatizam o conhecimento contextual. A autora faz a importante pergunta: o aumento da produção digitalizada produz menos racismo e menosprezo da vida da classe trabalhadora em nosso mundo contemporâneo? Ela também salienta que, com a inovação técnica, o conhecimento se torna cada vez mais fragmentado e os fragmentos são cada vez mais segmentados em componentes codificados e experimentais: o conhecimento geral em relação ao trabalho enfraqueceu nas últimas décadas. As contradições são visíveis no desenvolvimento do mundo fragmentado de hoje. O filósofo e pesquisador norueguês Olav Eikeland (2008) afirma que uma visão aristotélica de aprendizagem e conhecimento é congruente com um modelo de ensino da aprendizagem. Eikeland argumenta que essa visão deveria ser central para os pesquisadores em pesquisa-ação. Essas questões são centrais em toda pesquisa, assim como para o ensino em todas as áreas (KOSLYN; NELSON, 2017). Essas contradições estão presentes tanto para um professor universitário em um curso de Medicina quanto para o docente de carpintaria no ensino médio técnico, de Boston a Rio de Janeiro, Cidade do Cabo ou Oslo.

Sócrates questionou se a ciência e a filosofia de sua época estavam realmente em contato com o curso da vida humana. Pode-se fazer a mesma pergunta hoje. Com as recentes reformas educacionais, o tempo gasto nas salas de aula acadêmicas aumentou e o tempo de aprendizagem em oficinas diminuiu. Alunos e aprendizes nos ofícios profissionalizantes prosperaram e aprenderam quando estavam praticando nas oficinas, seja nas escolas profissionalizantes, seja no local de trabalho. Por outro lado, muitos não encontraram expressivo significado ou relevância nas salas de aula acadêmicas. Significado e motivação são dois lados da mesma moeda. Os alunos que observei e os que ensinei consideraram que as salas de aula acadêmicas contribuíram com pouco significado para sua vida futura, pois a base científica de sua aprendizagem prática foi apresentada como fenômenos muito distantes da realidade prática dos alunos. No entanto, a aprendizagem prática que encontraram nos workshops permaneceu com eles por toda a vida.

\section{A mentoria no modelo de ensino da aprendizagem}

A aprendizagem por meio de oficinas tem suas raízes nos cursos de aprendizagem, muito semelhante à forma como era praticada no sistema de guildas da Europa feudal. As guildas eram organizadas em três categorias: mestre, artesãos e aprendizes. Os idosos e os mais jovens trabalhavam e aprendiam juntos com as oficinas. A aprendizagem prática era a ordem do dia. O mestre demonstra, instrui e explica. 
Os aprendizes treinam e repetem, auxiliando uns aos outros com a ajuda do mestre, até realizarem as tarefas sem assistência - funcionando assim até dominarem o material que estão aprendendo. As escolas profissionalizantes, à medida que se desenvolveram na era industrial, seguiram a linha das tradições do sistema de guildas. Aqui, as oficinas eram a principal arena de aprendizagem. Por outro lado, há as tradições hierárquicas das escolas nas catedrais clássicas da Idade Média, onde os alunos se sentam em fileiras abaixo do professor, que professa ou dá aulas acima deles. Os alunos são disciplinados por horas e sua compreensão é avaliada e recebe uma nota de acordo com o que eles reproduzem nos exames (que normalmente são baseados em texto). As reformas na educação têm tentado desafiar essas tradições e fazer "os dois se encontrarem", embora com muito pouco sucesso.

Essas tradições fortemente contrastantes estão presentes e são visíveis no sistema educacional atual. Eles são parte integrante das contradições entre o trabalho manual e o mental, entre o trabalho intelectual e o manual, tal como se desenvolveu na sociedade nos últimos séculos. Esse contraste permeia as atividades e também é fundamental para a forma como se fazem perguntas na pesquisa científica (EIKELAND, 2008; MJELDE, 2016; SOHN-RETHEL, 1978).

\section{Novas vozes mentoras}

Novas vozes mentoras surgiram nas últimas décadas. As mulheres entraram no mundo científico e, do ponto de vista de gênero, levantaram novas questões fundamentais para a tradicional divisão social do conhecimento. As mulheres ingressaram como participantes em cargos acadêmicos e apresentaram teorias cruciais das formas predominantes de pensar nas ciências sociais e naturais. Uma questão central, levantada por homens e mulheres, é se os paradigmas científicos permaneceram encapsulados dentro daquelas tradições intelectuais que surgiram na Europa no século XVI, época em que houve o crescente domínio da ciência nas sociedades capitalistas ocidentais. O filósofo Thomas Kuhn, da Universidade de Berkeley, EUA, por exemplo, em seu livro A Estrutura das Revoluções Científicas, pediu uma mudança de paradigmas nas ciências naturais e sociais (BIRD, 2000; MORIN, 2008). Além dele, a socióloga canadense Dorothy E. Smith pede uma mudança de paradigmas em seu livro, Institutional Ethnography. A Sociology for People (Etnografia Institucional. Sociologia para as pessoas, em tradução livre) (SMITH, 2005). Nota-se, portanto, que os pedagogos têm buscado uma prática "Pedagogia para as pessoas" nos últimos cem anos.

Uma das pioneiras, tanto na profissão médica como revolucionária na pedagogia, foi a cientista italiana Maria Montessori. Ela foi a primeira mulher a ser autorizada a estudar medicina na Itália, em 1896. Ela é mundialmente famosa como filósofa e praticante de ciências da educação. Sua devoção à pesquisa e prática entre crianças carentes expandiu sua influência muito além da Itália. Em muitas partes do mundo, na Escandinávia e também na América Latina e na África, há jardins de infância e escolas inspiradas em Montessori. Ela se tornou uma inspiração e uma mentora 
para muitos cientistas da educação no século XX. Ela acreditava fortemente na capacidade de todos aprenderem e tinha profunda preocupação com a capacidade do professor de ajustar e resgatar as habilidades inerentes aos seres humanos. Um professor, ela argumentou, deveria ser um guia e um mentor (BEFRING, 2018).

A teoria sem prática seria um mero pensamento abstrato
Na década de 1970, o pesquisador brasileiro e pedagogo libertário, Paulo Freire, com seu livro Pedagogia do Oprimido, voltou a levantar novas questões básicas na agenda da Europa e também em outras partes do mundo. Seu livro teve uma grande influência na Escandinávia e foi traduzido para o norueguês em 1974. O ensino médio acadêmico foi atacado por estudantes na Noruega e novas experiências foram desenvolvidas no ensino fundamental e médio. Porém, simultaneamente, a divisão tradicional entre os caminhos acadêmico e profissionalizante continuou no sistema educacional público, apesar de novas políticas e esforços oficiais para integrar o ensino acadêmico e profissionalizante sob uma lei comum. A divisão entre caminhos acadêmicos e caminhos profissionalizantes/técnicos assumiu novas formas com a expansão do ensino médio, mas a tradicional divisão social do conhecimento continuou sendo um enigma. Uma característica central do trabalho de Paulo Freire ao longo de sua vida foi a dialética entre teoria e prática. A teoria sem prática seria um mero pensamento abstrato, assim como a prática sem teoria será reduzida a uma ação ingênua (FREIRE, 1998; FREIRE; VITTORIA, 2007). ${ }^{5}$

Paulo Freire tinha a opinião de que a escola tradicional tinha "um conceito bancário de educação", no qual o aluno era visto como uma conta-poupança a ser preenchida com informações obtidas do professor - economias que os alunos poderiam retirar posteriormente do banco. Como alternativa, ele sugeriu uma abordagem socrática: "uma pedagogia da pergunta". Na América do Norte, o trabalho de Paulo Freire no Brasil parece ser visto como pertencente a grupos marginalizados e à ideia de seu empoderamento. A visão europeia de seu trabalho segue uma tradição mais filosófica, com influências do trabalho da Escola de Frankfurt, tanto da década de 1920 como hoje (STROBELT, 2018).

A pedagogia crítica, desde o seu desenvolvimento na década de 1920, foi esquecida, mas surgiu novamente como um conceito na década de 1970. A pedagogia crítica surgiu da busca por maneiras alternativas de organizar o ensino e a aprendizagem em um sistema educacional em expansão. A pedagogia crítica tinha como objetivo geral mudar a sociedade, aumentando a conscientização política e promovendo a participação ativa no mundo. A práxis é o conceito central que Freire adota para capturar a relação dialética entre a consciência e o mundo. Ele foi inspirado pelas obras de Antonio Gramsci, Friedrich Engels e Karl Marx (MAYO, 2016). O conceito de práxis nesse contexto remonta aos antigos gregos e é central no trabalho de Paulo Freire. Seus escritos, que ecoam Marx, geralmente referem-se ao processo de conscientização, pelo qual as pessoas refletem sobre seu mundo de ação, da vida cotidiana, para examinar seus vários aspectos e gerar suposições sobre ele. Paulo 
Freire acreditava que a educação não podia ser dissociada da política: o ato de ensinar e aprender é considerado ato político em si. Ele definiu essa conexão como um princípio fundamental da pedagogia crítica.

Essa problemática é proeminente na obra de Karl Marx, tanto em O Capital quanto em suas obras filosóficas. Marx e Engels tinham especial preocupação com a divisão social do trabalho que observavam à sua volta no século XIX. Eles viram como a sociedade moderna avançada não conseguiu desenvolver o potencial do indivíduo. Marx procurou formas alternativas de desenvolver a escola, que abolissem a divisão social do trabalho na educação do futuro. Ele prestou atenção especial às escolas de formação artesanal, desenvolvidas na França após a revolução de 1848, que tentavam estabelecer um tipo de ensino secundário diferente do tipo acadêmico oferecido pelos liceus. A divisão social do conhecimento e as contradições entre a aprendizagem na escola e a aprendizagem nos locais de trabalho, entre o conhecimento geral e profissional, entre o trabalho intelectual e manual na formação da classe trabalhadora são as questões levantadas desde então. Desde Marx, ganha-se mais experiência e entendimento sobre essa divisão social devastadora do conhecimento. Da mesma forma, as mudanças revolucionárias contínuas da tecnologia exigem novas combinações entre práxis e conhecimento armazenado (MJELDE, 2006).

Algumas questões centrais são: podemos aprender com as tradições do mestre/ aprendiz no desenvolvimento da educação do futuro? Como o conhecimento armazenado pode ser integrado às práticas de aprendizagem nas escolas e locais de trabalho? Como integrar as disciplinas acadêmicas ao aprendizado na vida cotidiana de alunos da educação profissional, aprendizes e alunos do ensino fundamental e médio?

A atividade de aprendizagem em oficinas e locais de trabalho é baseada

Aprender por

meio da práxis

é uma forma revolucionária

de pensar em uma forma de conhecimento prático que, ao longo de milênios, foi montada e sistematizada. A aprendizagem ocorre por meio dos processos das próprias atividades, além da interação e cooperação com outras pessoas. Nesse modelo, a atividade em si é o ponto de rotação para a aprendizagem, quer esteja arrumando uma mesa, fazendo uma cirurgia em um paciente ou escrevendo uma tese. Aprender por meio da práxis é uma forma revolucionária de pensar sobre aprender e ensinar. A mentoria do mestre experiente e a mentoria mútua são aspectos centrais nos processos de aprendizagem. o papel do mestre é preparar o terreno e proporcionar condições para interação e cooperação entre os alunos e dar orientação. 0 desenvolvimento dos sistemas educacionais está repleto de contradições entre as tradições de aprendizagem "prática" e "acadêmica", um fato que mostra a relevância contínua dos filósofos gregos nas discussões atuais, conforme foi desenvolvido por grandes pensadores e praticantes nos últimos cem anos. 


\section{De Sócrates a Vygotsky na nova ciência da aprendizagem}

As questões levantadas por Sócrates e Aristóteles são centrais, hoje em dia, em todo o pensamento científico. As percepções científicas que evoluíram na Europa Ocidental no século XVI separavam mão, mente e coração e separavam o conhecimento artesanal do conhecimento intelectual. Uma das reflexões filosóficas de René Descartes é a acentuação de um conceito dualista do ser humano, afirmando, primeiro, que a mente humana consiste em não matéria (res cogitas), ou seja, é imaterial, enquanto o corpo é composto de matéria (res extansa); e, segundo, que mente e corpo não são apenas entidades diferentes, mas também separadas. 0 raciocínio humano e o fenômeno da mente foram estabelecidos como independentes do corpo (JOHNSON, 2008; BARATO, 2016). A compreensão do corpo baseavase em um modelo biológico que separava corpo e mente. Os cientistas que trabalham dentro dessa tradição geralmente consideram o conhecimento composto por linhas lógicas de pensamento, cada uma relativamente independente do corpo e da vida das pessoas em casa e no trabalho. Essa separação como construção social agora está sendo questionada tanto nas ciências naturais quanto nas sociais (MJELDE, 2016)

Paulo Freire expressou esse falso dualismo da seguinte maneira:

Escrevo com a cabeça, mas na verdade escrevo com todo o corpo. Não penso com minha mente, prefiro pensar com todo o meu corpo, com todas as minhas emoções, meus sentimentos, minhas intuições. Penso com minhas experiências de senso comum, com os fatos vividos, que embora raramente percebidos, ainda estão presentes em minha vida, e também com minha consciência reflexiva (FREIRE; VITTORIA, 2007, p. 110).

Como disse Maria Montessori: "as mãos são os instrumentos da inteligência humana" (BEFRING, 2018). Isso reflete o trabalho e a visão de Lev Vygotsky da década de 1920 (VYGOTSKY, 1962, 1978). A contribuição da Teoria da Atividade Histórico-Cultural (Cultural-Historical Activity Theory, CHAT), iniciada pelos psicólogos russos Lev Semenovich Vygotsky, Aleksei Nikolaevich Leontiev e Alexander Romanovich Luria, lançou uma luz inovadora sobre o desenvolvimento e a compreensão do processo científico e do aprendizado desenvolvido após a Revolução Russa ${ }^{6}$. Eles procuraram estabelecer uma abordagem da psicologia que lhes permitisse investigar como processos naturais, por exemplo, mecanismos sensoriais e maturidade física, entrelaçam-se aos processos culturais e, assim, determinam as funções psicológicas dos adultos. Vygotsky e seus colegas se referiram a essa nova abordagem como uma variação entre psicologia "cultural", "histórica" e "instrumental". Esses três rótulos indexam a centralidade da mediação cultural na constituição de processos psicológicos especificamente humanos e o papel do ambiente social interativo na estruturação dos processos pelos quais as crianças se apropriam das ferramentas culturais de sua sociedade no processo de seu desenvolvimento ontogenético.? 
Esses três pesquisadores forneceram uma análise histórica e social do desenvolvimento das funções mentais superiores dos seres humanos. Lev Vygotsky foi o principal cientista desse grupo. Uma característica importante do pensamento de Vygotsky é que um ser humano aprende do contexto social para o contexto individual e que o desenvolvimento da fala, consciência e pensamento humano deve ser entendido em suas circunstâncias sociais e históricas concretas. As pessoas desenvolvem sua atividade mental e psíquica indutivamente, falando e se comunicando com outros seres humanos. O pensamento e a linguagem não podem proficuamente ser estudados investigando os indivíduos sem suas conexões com os outros na sociedade, mas, sim, devem ser vistos de maneira interativa, de uma perspectiva material e de desenvolvimento, como membros de uma sociedade complexa e viva. Esse ponto de vista é de significado fundamental para toda pedagogia. A. R. Luria e A. N. Leontiev esclareceram ainda mais as descobertas de Vygotsky, mostrando a variação no desenvolvimento da consciência em relação às condições geográficas e ao contexto social.

Vygotsky criticou o ensino tradicional por ter uma visão atomística da aprendizagem. Entre outras coisas, ele sentiu que tanto a divisão das disciplinas escolares quanto a divisão do conteúdo pedagógico em disciplinas individuais contribuíam para a eliminação do significado das disciplinas individuais. O conhecimento, argumentou ele, não pode ser retirado de seu contexto natural e transmitido isoladamente. Só pode produzir sua riqueza de significado e criar motivação se for absorvido como parte de um todo. Ele lançou as bases para uma compreensão científica de como os seres humanos aprendem por meio da atividade e cooperação. Como disse Vygotsky: nem a mente nem a mão podem fazer muito sozinhas. A intenção se concretiza por meio de atividades e cooperação. Isso aponta para a transcendência das percepções tradicionais na atual divisão social do conhecimento na sociedade.

\section{Considerações finais}

Novos conhecimentos e práticas estão evoluindo. Pesquisas da neurociência e das ciências sociais sobre aprendizagem estão entrando em debates críticos na teoria educacional. A revolução tecnológica baseada nas TICs está mudando os processos de trabalho, reestruturando a produção e criando novas necessidades de habilidades em negócios e profissões. A lacuna entre a práxis da vida profissional e a aprendizagem teórica em faculdades e universidades aumentou. Essa lacuna desafia a aprendizagem e o ensino, tanto no ensino médio quanto no ensino superior em nosso mundo global.

Mas as contradições também fornecem as bases para novas perguntas e práticas desafiadoras nas instituições de ensino. As teorias de aprendizagem enraizadas nas tradições de mestres/aprendizes levantam questões fundamentais e perturbadoras sobre a separação não natural que os sistemas educativos proporcionam, 
separando-nos de nossa própria humanidade. Como desenvolver conceitos a partir das tradições de aprendizagem experimental dos trabalhadores? Mike Rose (2014) pergunta se dentro dos empreendimentos em educação profissional houve pouca atenção às dimensões intelectuais do trabalho comum, às possibilidades cognitivas do salão de cabeleireiro, da oficina de soldagem e do canteiro de obras. 0 problema está presente quer você estude para ser enfermeiro, médico, mecânico de automóveis, engenheiro ou cabeleireiro (BARATO, 2011, 2016; MJELDE, 2015a, p. 22, 2020).

Novos conceitos relevantes para o século atual são a pedagogia e a didática vocacionais. Elas se baseiam em conceitos e práticas de acordo com a forma como os jovens nas oficinas de ensino profissionalizante aprendem por meio de atividades e em cooperação com um mentor e uns com os outros. Esses termos e práticas têm muito em comum com os processos de aprendizagem encontrados nas tradições de Dewey, Freinet, Freire e Montessori, de acordo com o entendimento científico da teoria da atividade de Lev Vygotsky. Também são formas de pensar sobre aprendizagem e conhecimento, seguindo o Método Socrático, conforme descrito nos escritos de Aristóteles. O conceito de pedagogia das profissões se desenvolveu em relação a esses conflitos e contradições no ensino superior e novas portas se abrem para a adoção das tradições de mestre/aprendizagem com mentoria e cooperação entre os alunos. Tudo isso promete um futuro melhor para a educação em toda a parte.

\section{Notas}

'Este artigo é uma versão ampliada de um discurso sobre mentoria apresentado no $1^{\circ}$ Congresso Internacional da Associação Europeia de Professores Eméritos (European Association of Professors Emeriti, EAPE), em Atenas, Grécia, em 31 de maio de 2019.

${ }^{2} \mathrm{O}$ ensino público obrigatório de sete anos foi ratificado pelo Parlamento norueguês em 1889.

${ }^{3} \mathrm{Na}$ Noruega, o Parlamento ratifica as leis sobre questões educacionais. As escolas e universidades são, na sua maioria, públicas e gratuitas.

${ }^{4}$ Problemas semelhantes também fazem parte da realidade sueca, dinamarquesa e finlandesa. Essas sociedades, assim como a Noruega, desenvolveram-se com sistemas educacionais iguais na era do pós-guerra (ALB/EK et al., 2019; GOTTLIEB, 2018).

${ }^{5}$ Este artigo utiliza os dois conceitos discutidos, prática e práxis. A aprendizagem por meio de oficinas nas escolas é tradicionalmente chamada de prática na Noruega. Substituí o conceito "teoria" em minhas discussões por "aprendizagem". Chamo de "conhecimento armazenado".

${ }^{6}$ Ao que tudo indica, diferentes caminhos estão sendo seguidos na América do Norte e na Escandinávia em relação à contribuição das tradições da CHAT. A pes- 
quisa nas Américas parece ser direcionada a grupos marginalizados, enquanto na Escandinávia é mais direcionada a epistemologia, educação profissional e mercado de trabalho (KVALE, 1993; ENGESTRØM, 1996; PORTES; SPENCER, 2011).

7 Jean Piaget trabalhou nessas questões na Suíça ao mesmo tempo, de um ponto de vista biológico. Seu ponto de partida para a pesquisa foi o desenvolvimento de seus filhos. Discuti as contribuições de Jean Piaget e Lev Vygotsky em meu outro trabalho.

\section{Agradecimento}

Agradeço a Jarbas Novelino Barato e Peter Mayo pela ajuda na construção deste artigo.

\section{Referências}

ADAMSON, Glenn. Thinking through craft. Oxford: Berg Publishers, 2007.

ALBAEK, Karsten et al. Better late than never?: how late completion affects the early careers of dropouts. IZA Discussion Paper, [s. I.], n. 12560, p. 1-39, Aug. 2019.

BAKKEN, Anders; ELSTAD, Jon Ivar. For store forventninger: kunnskapsløftet og ulikhetene i grunnskolekarakterer. Oslo: Norsk institutt for forskning om oppvekst, 2012. (NOVA Rapport, 7/12).

BARATO, Jarbas Novelino. Saber do trabalho, aprendizagem situada e ensino técnico. Boletim Técnico do Senac, Rio de Janeiro, v. 37, n. 3, p. 19-29, 2011.

BARATO, Jarbas Novelino. Trabajo, conocimiento y formación profesional. Montevideo: OIT/Cinterfor, 2016.

BEFRING, Edvard. De pedagogiske kvalitetene: løfterike muligheter for barn og unge. Oslo: Universitetsforlaget, 2018.

BIRD, Alexander. Thomas Kuhn. Chesham: Acumen, 2000.

BOURDIEU, Pierre; PASSERON, Jean-Claude. Les étudiants et leurs études. Paris: Walter de Gruyter, 1964.

CHIASSON, Dan. The man who built the Bauhaus. The New Yorker, New York, 29 Apr. 2019. Disponível em: https://www.newyorker.com/magazine/2019/04/29/theman-who-built-the-bauhaus. Acesso em: 22 jul. 2020. 
COOPER, Linda. Conceptual and practical knowledge in workers' education. In: VET CONFERENCE, 2018, Zürich. Annals [...]. Zurich, [s. n.], 2018.

DEWEY, John; DEWEY, Evelyn. Schools of tomorrow. New York: E. P. Dutton \& CO., 1962.

EIKELAND, Olav. The ways of Aristotle: Aristotelian phronesis, Aristotelian philosophy of dialogue, and action research. Bern: Peter Lang, 2008.

ENGESTRØM, Y. Developing work as educational research: looking back ten years into the zone of proximal development. Nordisk Pedagogikk, [s. I.], v. 16, n. 3, 1996.

FREIRE, Ana Maria Araújo; VITTORIA, Paolo. Dialogue on Paulo Freire. Interamerican Journal of Education for Democracy, [s. I.], v. 1, n. 1, p. 96-117, Sept. 2007.

FREIRE, Paulo. Pedagogy of the heart. New York: Continuum, 1998.

GOTTLIEB, Susanne. How Denmark try to solve the problem of dropout in vocational education. New Journal, [Nagoya], n. 17, p. 48-57, 2018.

GRIGNON, Claude. L'ordre des choses: les fonctions sociales de l'enseignement technique. Paris: Edition de Minuit, 1971.

JOHNSON, Mark. The meaning of the body: aesthetics of human understanding. Chicago: University of Chicago Press, 2008.

KOSSLYN, Stephen; NELSON, Ben. Building the intentional university. Massachusetts: The Mit Press 2017.

KVALE, Steinar. En pædagogisk rehabilitering af mesterlæren?. Dansk pædagogisk tidsskrift, [s. I.], v. 41, n. 1, 1993.

LIVINGSTONE, David W. (ed.). Critical pedagogy and cultural power. [S. I.: s. n.], 1987.

MAYO, Peter. Praxis. In: Peters Michael A. (ed.). Encyclopedia of educational philosophy and theory. Singapore: Springer, 2016.

MJELDE, Liv. Apprenticeship: from practice to theory and back again. Joensuu: University of Joensuu Press, 1993.

MJELDE, Liv. From hand to mind. In: LIVINGSTONE, David W. (ed.). Critical pedagogy and cultural power. [S. I.: s. n.], 1987. p. 205-221. 
MJELDE, Liv. Labour and learning: the apprenticeship program in Norway. Interchange, [s. I.], v. 21, n. 4, p. 34-48, 1990.

MJELDE, Liv. Learning through praxis and cooperation: Lev Vygotsky and vocational pedagogy. In: MARHUENDA-FLUIXA, Fernando (ed.). Vocational education beyond skill formation. Bern: Peter Lang, 2017.

MJELDE, Liv. The magical properties of workshop learning. Bern: Peter Lang, 2006.

MJELDE, Liv. Mentoring experience and meaning. In: COKKINOS, Dennis V. et al. (ed.). The capital of knowledge. Athens: Society for the Propagation of Useful Books, 2020.

MJELDE, Liv. Mentoring our knowledge for the future. Athens: European Association of Professor Emeriti, 2016. Keynote speech.

MJELDE, Liv. Mentoring vocational self-reliance: lessons from Uganda. In: MOLZBERGER, Gabriele; WAHLE, Manfred (ed.). Shaping the futures of (vocational) education and work. Bern: Peter Lang, 2015. p. 101-124.

MJELDE Liv. The promise of alternative pedagogies: the case of workshop learning. In: WATSON, K. et al. (ed.). Educational dilemmas: debate and diversity. London: Cassell. 1997. p. 331-340.

MJELDE, Liv. Las propiedades magicas da la formacion en el taller. Montevideo: OIT/Cinterfor, 2015a.

MORIN, Edgar. On complexity. New Jersey: Hampton Press, 2008.

NORWAY. Ministry Knowledge. Kompetansereformen- Lære hele livet. Oslo: Ministry of Knowledge, 2020. (Stortingsmelding, 14).

NORWAY. Ministry of Knowledge. På rett vei. Kvalitet og mangfold i fellesskolen. Oslo: Ministry of Knowledge, [2013?]. (Norwegian Official Report, 20).

PAVLOPOULOS, Prokopios. The Roots of learning: the mentor's role. In: COKKINOS, Dennis V. (ed.). The capital of knowledge. Athens: Society for the Propagation of Useful Books, 2020.

PORTES, Pedro. R.; SPENCER, Salas. Vygotsky in 21st society: advances in cultural historical theory and praxis with non-dominant communities. New York: Peter Lang, 2011. 
ROSE, Mike. The mind at work: valuing the intelligence of the American worker. New York: Penguin, 2014.

SMITH, Dorothy E. Institutional ethnography: a sociology for people. Lanham: AltaMira Press, 2005.

SOHN-RETHEL, Alfred. Intellectual and manual labour: a critique of epistemology. London: Macmillan, 1978.

STROBELT, Michael. Kritisk pedagogikk - et svar på dagens kunstpedagogiske utfordringer? Journal of Research in Arts and Sports Education, Oslo, v. 2, n. 2, p. 4-18, 2018.

VYGOTSKY, Lev. Mind in society: the development of higher psychological processes. Cambridge: Harvard University Press, 1978.

VYGOTSKY, Lev. Thought and language. Cambridge: MIT, 1962. 